\title{
Employee Proactiveness to Engage in Sustainable Consumption Leading to Societal Benefits
}

\author{
Laura Salciuviene ${ }^{1}$, Veronica C. Buenaventura ${ }^{2}$, Kelvin Lee $^{3}$
}

${ }^{1}$ Kaunas University of Technology

K. Donelaicio str. 73, LT-44249 Kaunas, Lithuania

E-mail.laura.salciuviene@ktu.lt

${ }^{2}$ Momentum Worldwide Singapore

40A Orchard Road 09-01, the MacDonald House Singapore 238838

E-mail.erikab@gmail.com

${ }^{3}$ Nanyang Technological University

42 Nanyang Avenue, Student Service Centre Level 1 Singapore 639798

E-mail.cskelvinlee@ntu.edu.sg

cross $^{\text {ref }}$ http://dx.doi.org/10.5755/j01.ee.30.1.17385

\begin{abstract}
Our manuscript aims to advance our understanding of employee engagement in sustainable consumption through collaborative learning. Learning is one of the keys to sustain competitive advantage and to keep business fresh and relevant in a constantly evolving global business environment. Consequently, collaborative learning is a crucial skill that companies expect their prospective employees to demonstrate at work. In our study, we hold that collaborative learning will increase employee proactiveness to engage in sustainable consumption when moral identity is present. Moral identity refers to a moral state that is internal and projected to others and therefore consists of two dimensions: internalization and symbolisation. Moral identity along with collaborative learning and employee proactiveness to engage in sustainable consumption at a workplace leading to societal benefits (i.e., economic, social and psychological) in the housing, mobility and food consumption domain has not received much attention in academia. We theoretically investigate this phenomenon in the context of massively-multiplayer online video games and offer a conceptual model. In our study, we conceptually put forward propositions linking moral identity, engagement in sustainable consumption and societal benefits along with antecedents of collaborative learning: achievement, social presence, immersion and video game frequency. Based on our conceptual model, we provide implications for public policy makers and practitioners.
\end{abstract}

Keywords: Employee Proactiveness to Engage in Sustainable Consumption; Antecedents of Collaborative Learning; Moral Identity; Societal Benefits; Massively-Multiplayer Online Video Game Context.

\section{Introduction}

Massively multiplayer online video games have a $27 \%$ share of global gaming industry revenues in 2016 (Adams, 2016) with predicted $\$ 100$ billion in 2019 (Takahashi, 2016). Over the last few years massively multiplayer online video games have become widespread among individuals, especially among younger generations. According to McGonigal (2010), video games are played by over 500 million gamers in the world and this figure is increasing rapidly, predicting another 1.5 billion gamers over the next ten years. Tapscott (2009) mentions that gamers prioritise online video games over TV, spending three times longer on playing video games rather than watching television (Yee, 2005). Today, the video game industry is bigger than the film industry, with nearly 50 percent of its revenue accountable to a genre of video games called the massively multiplayer online video games (Kushner, 2005).

A young individual, aged below 21, who spends all his/her spare time to play online video games would represent a profile of an average online video games player in a developed country (MxGonigal, 2010). Also, there are professional online video game players, who play those games for living (BBC news, 2005). Given the focus on our research on employees, we include a segment of young people in the online video game market that was born between 1982 and 2001. This segment is called Millennials and massively multiplayer online video games have been very popular among this group of individuals (Howe \& Strauss, 2000). This segment of online video game market usually represents technologically savvy, multi-tasking, disloyal and collaborative group of individuals (e.g., Lipkin \& Perrymore, 2009). The literature refers to Millenials as video game consumers (Simpson, 2015).

Although massively multiplayer online video games attract millions of Millennial players who invest their time and money to play online video games, little research exists that deepens our understanding of how to stimulate socially responsible behaviour of this group. Although previous research offers some guidance and implications for public

\footnotetext{
1 Correspondence: Dr Laura Salciuviene, Lancaster University Management School, ADDRESS: Lancaster University, Lancaster, LA1 4YX, United Kingdom, Tel. +44(0)1524 510688, Email: 1.salciuviene@lancaster.ac.uk
} 
policy makers that political orientation, morality and sustainable consumption are linked, and offers three segments of consumers adopting sustainable consumption (e.g., Watkins et al., 2016), research on how to promote and enhance engagement in sustainable consumption of employees at a workplace is still in its infancy. Our study suggests that collaborative learning that Millenials engage with during online games could be one way to stimulate responsible and sustainable consumption of Millenials' age group within the three key areas responsible for the highest proportion of $\mathrm{CO} 2$ emissions: food, mobility and housing.

Traditional approaches to collaborative learning are faceto-face discussions (Chiu, 2008), but since the advent of new technologies, computer-supported discussions, chat rooms (Chen \& Chiu, 2008) and online games such as massively multiplayer online video games (Kong \& Kwok, 2009) have become popular approaches to collaborative learning. Aside from offering benefits, such as cognitive superiority and improved personality traits that allow learners to partake in more superior collaborative learning and working (Bargh \& Schul 1980), collaborative learning in the workplace is very desirable as it offers many benefits. It allows employees to learn faster (o'Keeffe, 2002) and develops better problemsolving and decision-making skills through connections with co-workers and managers of varying areas and degrees of expertise (McHugh, 1998). These are outcomes, which are important to organisations but challenging to achieve for reasons such as low motivation to collaborate (Laister \& Koubek, 2001). At an individual level, Panitz (1997) identified that collaborative learning provides academic, social and psychological benefits.

Since massively multiplayer online video games have emerged as a positive platform for collaborative learning, we use massively multiplayer online video games as a context for our research. In our study, we define massively multiplayer online video games as "highly interactive video games where players have freedom to create their own "avatars" and use those to play games solo, interact with computer-mediated avatars or other players' avatars" (Steinkuehler, 2004a: 78; 2004b).

To our knowledge, no research exists that offers a conceptual model representing moral identity to enable employees to exhibit responsible behaviour towards interests of others using online video games. To date, no previous research has offered a conceptual model that combines moral identity, collaborative learning in an online environment and its consequences. Our research is original because it posits the consequences of collaborative learning that happen in an online environment and explains how to use this model to enhance responsible and sustainable consumption of employees to increase the engagement with the needs and interests of society and reduce harm to others (e.g., overconsumption, inequality of wealth, Watkins et al., 2016). Further, our research suggests that employees could use their collaborative learning skills to engage with responsible and sustainable consumption and we use international entrepreneurship theory to explain employee proactiveness to engage with responsible and sustainable consumption of employees. In other words, higher achievement motivation leads to higher collaborative learning, consequently, enhancing higher proactiveness to engage with responsible and sustainable consumption. This link is moderated by moral identity, explaining the level of engagement in sustainable consumption leading to societal benefits within three key areas responsible for the highest proportion of $\mathrm{CO} 2$ emissions: food, mobility and housing.

\section{Theoretical Model and Propositions}

\section{Earlier Research in Massively Multiplayer Online Video Games}

Massively-multiplayer online video game popularity has increasingly gaining attention of academic research with a focus on both positive and negative effects of massively multiplayer online video game play on individuals.

Previous research studying massively multiplayer online video games and collaborative learning demonstrates that collaborative learning within virtual worlds is fostered due to the nature of the way massively multiplayer online video games are played and the elements within it (such as reward system and stimuli). (McGonigal, 2010). However, those studies do not suggest the reasons as to how learning within game-based environments manifests itself in real life. For instance, a player may engage in collaborative learning activities within the game environment but only because the game design and structure dictates this method of learning (McGonigal, 2010). Little research exists on addressing the question how massively multiplayer online video game play could be used to encourage employees to utilise skills acquired through collaborative learning to engage with responsible and sustainable consumption responsible for the highest proportion of $\mathrm{CO} 2$ emissions: food, mobility and housing. Our research suggests that moral identity dimensions could be a moderating factor manifesting the level of engagement in sustainable consumption responsible for the highest proportion of $\mathrm{CO} 2$ emissions: food, mobility and housing, while International Entrepreneurship theory could explain the level of readiness/responsiveness of employees to act in an responsible and sustainable way within the three main areas responsible for the highest proportion of $\mathrm{CO} 2$ emissions: food, mobility and housing.

\section{Conceptual Model and Propositions}

We present our conceptual model (see Figure) for our study, which comprises predicted theoretical links with propositions to be further tested in other empirical studies. Before providing a conceptual background for our propositions, we emphasise three key areas, that is, food consumption, housing and mobility/transport (Spaargaren 2011, Liu et al., 2016) that this study looks at in terms of engagement in sustainable consumption and benefits gained from it. We selected those key areas for the following reasons:

(a) all those areas are linked to energy consumption in terms of producing or consuming products within those areas (McLaren \& Childs, 2013, Liu et al., 2016), while unnecessary energy consumption is directly linked with responsible and sustainable consumption - the key concept of this study;

(b) we follow three basic assumptions: 1) sustainable consumption cannot happen without a consumer and his/her consumption habits; 2) sustainable consumption happens in 
social surroundings; 3) the link between the "systems of provision" and the sustainable consumption behaviour have to be looked at (Liu et al., 2016). Below we briefly outline those key areas.

Food consumption is associated with health risks (Liu et al., 2016) and food production and consumption account for nearly $30 \%$ of energy emissions to the environment (FAO, 2013 in Liu et al., 2016).

Housing domain is the second largest area contributing $26 \%$ to the greenhouse gas emissions to the environment (Hertwich \& Peters, 2009, in Liu et al., 2016)

Mobility refers to sustainable transport to physically move around (Liu et al., 2016). Sustainable mobility accounts for $23 \%$ of CO2 emissions (IEA, 2012, in Liu et al., 2016).

\section{Employee Proactiveness Orientation and International Entrepreneurship Theory}

Employee proactiveness could be related to innovation, career progression and career satisfaction (Seibert et al., 2001, in Bakker et al., 2008). Crant et al. (2000, in Bakker et al., 2012) explains proactiveness as positively influencing employee attitudes and behaviours as "proactive individuals identify or create opportunities that create favourable conditions for individual or team effectiveness" (ibid, p.1361).

The above proactiveness orientation can be related to international entprepreneurship theory, explaining behaviours of employers in an international environment, based on the characteristics of an employer (e.g., exploring and identifying opportunities and devising a strategy how to use those opportunities to benefit from them) (de Mattos \& Salciuviene, 2017).

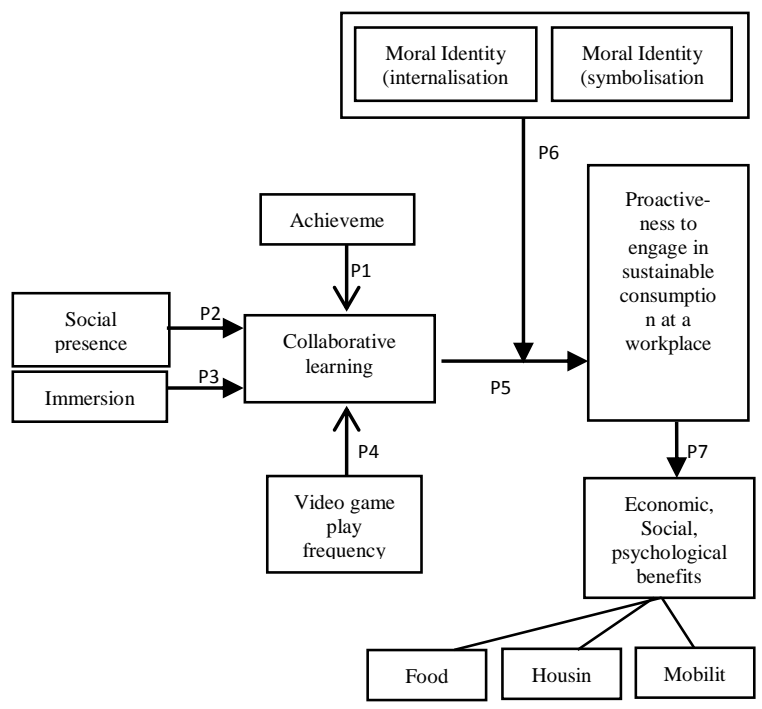

Figure. Conceptual Model

\section{Moral Identity, Employee Proactiveness to Engage in Sustainable Consumption and Societal Benefits}

In our study we adopt McFerran's et al. (2010) definition of moral identity, which is "a mental representation of one's moral character that is held internally and projected to others" (p.37). Given that moral identity is linked to an individual's responsible ideology, defined as a set of "beliefs, values, standards and self-assessments that define an individual's orientation toward matters of right or wrong"
(McFerran et al., 2010:35), we posit that moral identity could act as a moderator between collaborative learning and engagement in sustainable consumption of employees within the three key areas responsible for the highest proportion of $\mathrm{CO} 2$ emissions: food, mobility and housing.

Moral identity has been examined in earlier studies. Barclay et al. (2014 p.17) state that "moral identity provides the motivational impetus for acting in a way that is consistent with individuals' understanding of how a person ought to behave under a given set of circumstances". For example, past research in the consumption domain suggests that moral identity affects altruistic behaviour (Reed II et al., 2016, in Wu \& Yang, 2018) and is positively linked to sustainable behaviour (Karmarkar \& Bollinger 2015; Jia et al., 2017 in Wu \& Yang, 2018) and beliefs (Chowdhury and Fernando, 2014, in Wu \& Yang, 2018). However, other studies find no relationship between moral identity and sustainable behaviour (Crimston et al., 2016, in Wu \& Yang, 2018).

Furthermore, past research suggests that moral identity affects individual resilience, while it also influences community social capital (Hart et al., 1998) and moral identity is defined as "a self-consistent commitment to lines of action benefiting others (p.513). Mayer et al., (2012) suggest that moral identity positively influences responsible leadership, which is defined as the leader's ability to punish or reward responsible behaviour of their employees resulting in more responsible behaviour and lessens conflicting behaviour among employees at a workplace (Mayer et al., 2012). Given the above findings, we posit that proactiveness would be an important consequence of collaborative learning that is moderated by moral identity. Therefore, two dimensions of moral identity (i.e., Symbolization and Internalization) would manifest themselves in enhancing higher or lower levels of employee proactiveness to engage with responsible and sustainable consumption within the three key areas responsible for the highest proportion of $\mathrm{CO} 2$ emissions: food, mobility and housing, leading to societal benefits, that is, social, economic and psychological benefits within three key domains of $\mathrm{CO} 2$ emissions: food consumption, housing and mobility.

Video game industry now is competing with film industry (Harford, 2017), economicaly, labour market benefits from video game players' subscribtions and purchases of video games in terms of creating new jobs, more online video games can be created and that will lower subscription cost, more individuals can play online video games, more social activities will happen within MMOG games.

When an employee is engaged with responsible and sustainable consumption in food, housing and mobility activities, he/she benefit economically themselves and provide societal benefits to the community. For example, eating more sustainable (i.e., organic) food will enable more farmers to grow organic food at a lower cost, more people within the community will be able to afford it, more farmers will have jobs, there will be less negative impact on the environment.

Social benefits would be linked to relationships and socialising when playing online video games (Hazel, 2018a) and those are closely linked with psychological 
benefits of interaction. However, in the context of engagement in sustainable consumption in food, housing and mobility responsible and sustainable activities, employees would benefit from building relationships with community members and interact with other people having similar preferences for food, housing and mobility responsible and sustainable activities.

Psychological benefits from playing online video games could be improved mood, relaxation, reduced anxiety and stress (Hazel, 2018b), but in terms of engagement in sustainable consumption in the following four areas, such as food, sports, health and mobility, psychological benefits might be different. For instance, while engagement with mobility sustainable consumption might offer reduced stress and anxiety, but when a customer decides to walk instead of driving a car, those psychological benefits become less apparent due to increased time required to reach the final destination and therefore, anxiety can intensify, while the level of improved mood from walking can decrease considerably.

\section{Social Presence as an Antecedent of Collaborative Learning in Massively Multiplayer Online Video Games}

A motivating factor for a personality to engage with video games refers to Social presence (or social context/socialness) and it comprises "socialising (being interested in other players, communication with them) relationship (seeking to form long-term relationships with other players) and teamwork (achieving satisfaction from being a group member, a team player and achieving his/her goals as being a part of a group)" (Yee, 2007 p.773).

In the setting of massively multiplayer online video games, social context of game play is another dimension that video games could have an effect on. This dimension "may change the effect of content, such as how the social context of game play may enhance some effects when playing a massively multiplayer online video game" (Gentile et al., 2009 p.752). Players can enjoy the game with limited social interaction; however, to be able to engage in certain game content that is more difficult (subsequently offering higher rewards to progress), they have no choice but to seek help from other players (O'Reilly, 2010). To gain rewards, players have to work together toward a common goal and they are required to interact with other avatars. Parties and raids are among several ways players in massively multiplayer online video games can interact through (Nardi \& Harris, 2006) as players are required to work together to complete the tasks. To gain rewards in massively multiplayer online video games, communication and collaboration within the game as well as outside the game (through discussion forums or Skype) are crucial and teams that work together gain their rewards easier and progress to another level faster (Voulgari \& Komis, 2011).

\section{Immersion as an Antecedent of Collaborative Learning in Massively Multiplayer Online Video Games}

Immersion is another important motivating factor for an gamer to engage with the context of online video games, Immersion comprises "discovery (finding things, exploring things), role playing (improvising with other players, fantasising while communicating with other players), customisation of game characters and escapism from real lives / relaxation" (Yee, 2007 p. 773-774).

\section{Social Learning Theory and Collaborative Learning}

The roots of collaborative learning as a focus for researchers, began as early as the 1970s, but major breakthroughs stemmed from researchers who borrowed Piaget's (1972) theory of cognitive development, who stated that an individual continuously learns by engaging in a cycle of an interaction with others, developing himself through his/her own experiences and by observations of other people surrounding them, therefore allowing him to partake in more sophisticated social interactions, and developing himself even further.

Another theory by Bandura (1977, in McLeod, 2016) suggests that social learning occurs not only through punishment and rewards but also by observing other people's behaviour. For example, children observe parents and teenagers observe celebrities on TV. Those people who could be observed should be influential to learn from their behaviour and follow it by observers with their own actions.

According to Social Learning Theory, people learn by experiencing things themselves or by observing others (Mischel \& Shoda, 1995), whether they are psychically present in front of the TV or virtually - in a video game. When observing others' behaviour, people can see whether they are rewarded or punished (McLeod, 2016). For example, Buckley and Anderson (2006 p.368) believe that video games allow people to "learn many behaviours, attitudes, expectations, beliefs and perceptual schemata through observation and participation in them". This is especially applicable to massively multiplayer online video games where there are many other players to observe their achievement or learn from their mistakes.

According to the Social Learning Theory, any stimulus is posited to have sort-term and long-term effects through several learning mechanisms (Buckley \& Anderson, 2006). Therefore, the most pertinent to this research are the following determinants: frequency of game play (Stone and Gentile, 2008), achievement, social-ness and immersion in massively multiplayer online video game (Yee, 2007) that influence promotion of collaborative learning [defined as promoting situations in which two or more people learn or attempt to learn together as opposed to individual learning options (Dillenbourg, 1999)].

In our study, we find inspiration in Senge (1990) and define Collaborative Learning as a process of developing a willingness to collaborate with other members of a group aiming to achieve the desired outcome. Collaborative learning is viewed as an effective way of learning in both academic and organizational settings (e.g., Panitz, 1996) and 
contributes to the organization's major competitive advantages (Senge, 1990).

\section{Motivation and Collaborative Learning}

Motivation is the force that drives people to do the things they really do (Barrick et al., 2002 Sansone \& Harackiewicz, 2000; Nohria et al., 2008) or their learning (Weiner, 1972 Pintrich, 1999; Masgoret \& Garder, 2003; Shih \& Gamon, 2001).

Earlier research suggests that motivation can be either intrinsic or extrinsic (e.g., Benabou \& Tirole, 2003). Intrinsic motivation refers to motivation that stems from within the individual (for instance, a genuine interest or enjoyment within the task), while extrinsic motivation refers to motivation that comes from external sources (for example, monetary or other material rewards) (ibid, 2003).

Both intrinsic and extrinsic motivation can be found in massively multiplayer online video games, which contain many elements that players find interesting or enjoyable (intrinsic), while other elements offer multiple rewards to players (extrinsic) who work hard in those video games to achieve those rewards. However, the motivations of each player may differ from those of another player when a player engages in the same video game's activities (Schultheiss, 2007; Bartle, 1996, 2004; Yee, 2006, 2007). Therefore, it is reasonable expect that the outcomes of the player's in-game experiences (such as, in the case of this research, collaborative learning and proactiveness to consumer responsible food products) can be influenced by the player's motivation.

\section{Achievement as an Antecedent to Promote Collaborative Learning in Massively Multiplayer Online Video Games}

We find that Achievement is an important motivating factor of personality to engage with online video games and it comprises "advancement (e.g., power gain, rapid progress, gaining status symbols in a game), mechanics (analysing game rules to become a better player in a game) and competition (desire to compete with others in a game, challenge them to achieve competitive status)" (Yee, 2007 p.773). We define it as a motivating force to succeed while realising his/her goals to achieve and it contributes to faster learning how to compete and succeed in an online video game environment.

\section{Massively Multiplayer Online Video Game Play Frequency as a Motivating Factor for Promoting Collaborative Learning}

The literature review on previous studies in terms of game play frequency suggests those could be divided into two groups: studies that focus on concerns/pathological issues arising from amount of game play and studies focusing on positive aspects of amount of game play. For instance, Stone \& Gentile (2008) found that the effects of the amount of game play are mostly related to activity displacement (i.e., if more time is spent playing video games, there is less time for studying or exercising) rather than to collaborative learning. More time spent playing games is positively correlated with obesity (Subrahmanyam et al., 2000) or other health issues (Brasington, 1990). Players who are driven by achievement, for instance, may spend excessive amount of time advancing their characters to the highest possible level, but as soon as an expansion pack is released, there is a newer and higher benchmark for that achievement that requires spending even more time in attaining these new goals. Thus, with increasing amounts of game play that are required to achieve bigger and better rewards in that specific circumstance for players who are continuously exposed to the experiences (stimuli) the game provides, play frequency might not result in better collaborative learning experience, even though players engage in collaborative activities within the game, but they might focus on their own achievements and play alone at those moments without considering the need to observe other players so often, from which collaborative learning occurs.

However, other research has shown that repetition of any activity, including those in video games, facilitates learning through role learning (Perkins, 1914, Hovland, 1938). McGonigal's (2011) conceptual work states that spending more time playing bigger and better games will produce collaborative learners. For instance, a player who is motivated by achievement will participate in highly rewarded activities because of perceived value of the rewards associated with the achievement in that particular context. It is reasonable to suggest that constant, repetitive stimulus that payers would receive during video games may have an effect on the player's achievement within the game and would enhance the development of important collaborative problem-solving skills that is a natural skill for video gamers to develop as a result of observing mistakes of others during the game and learning through discussions with others and taking collaborative decisions how to prevent those mistakes in the future (Prensly, 2007; Hubbard, 2009).

Based on the above, we propose the following propositions:

P1: Achievement will positively influence collaborative learning.

P2: Social presence will positive influence collaborative learning.

P3: Immersion will positively influence collaborative learning.

P4: Video game play frequency will positively influence collaborative learning.

P5: Collaborative learning will positively influence employee proacti-veness to engage with responsible and sustainable consumption.

P6: Moral identity will moderate the collaborative learning and employee proacti-veness to engage with responsible and sustainable consumption link.

P7: Employee proacti-veness to engage with responsible and sustainable consumption will positive influence societal benefits.

In our research, we use international entrepreneurial orientation to uncover the entrepreneur (Lumkin, 2011; De Mattos \& Salciuviene, 2017) who could have high or low propensity to engage with responsible and sustainable consumption depending on moral identity dimensions that could be manifested through different types of international entrepreneurial orientation in engaging with responsible and sustainable consumption. We posit that 
highly proactive, innovative Millenials would have a tendency to manifest higher engagement in sustainable consumption within the three key areas responsible for the highest proportion of $\mathrm{CO} 2$ emissions: food, mobility and housing, while less proactive employees will be less willing to engage with responsible and sustainable consumption, but using theory of hierarchical progression (Wooliscroft et al., 2013 in Watkins et al., 2016) enabling simple steps of collaborative learning in online video games could gradually move those employees to higher engagement with responsible and sustainable consumption within the three key areas responsible for the highest proportion of $\mathrm{CO} 2$ emissions: food, mobility and housing.

\section{Conclusion}

The paper aims to gain a deeper understanding of links among moral identity, factors enhancing collaborative learning with online video games, employee proactiveness to engage with responsible and sustainable consumption and societal benefits. To date, no previous research has offered a conceptual model that combines moral identity, collaborative learning in an online environment and its consequences. Our research provides implications for public policy makers, seeking to use collaborative learning to achieve societal benefits in terms of responsible and sustainable consumption. For example, online video games could be used for younger generations to educate them about how to maintain a balanced lifestyle or how to reduce $\mathrm{CO} 2$ emissions by reusing unwanted goods and gifts by donating those to charities and incorporate second-hand goods from eBay in their lives both at work and home environment.

For instance, public policy makers could offer an online video game, where Achievement would become important for employees to engage with responsible and sustainable consumption in the game. In this case, Achievement would motivate employees to engage with a responsible and sustainable consumption activity through an online video game allowing users to experience different roles when consuming responsibly and sustainably in all three domains, i.e., food, housing and mobility, to explore and, therefore, learn things in situations they would be able to experience in real lives resulting in learning and application of their skills at a workplace.

Previous research underlines the importance of an online video game play frequency and learning. In fact, the amount/frequency of video game play is an important factor in massively multiplayer online video games because of its ability to engage players with the games, who are ready to play frequently and, therefore, ready to spend large amounts of time (and their income) on those video games (Nardi \& Harris, 2006). However, there might be some drawbacks of the amount of time employees would spent on the online video games. One reason might be due to the large numbers of players on an online video game platform, where communication within the game and outside the game would require different skills and the players within teams would not hold the same skills because of changes of players within a team. Another reason might be due to inability to join well-formed teams, and, therefore, newer players would have to create their own teams. The team formation would require extra time and effort that not all players would be dedicated to give and, therefore, would prefer to play on their own and be satisfied with smaller rewards, but they would lack the advancement of teamwork and relationship building and management skills because they would be playing a game alone. Therefore, the lack of teamwork and relationship management skills in an online video game might enhance collaborative learning skills less so.

\section{Future Research Directions}

As with any other research, this manuscript has limitations that indicate future research directions.

First, while previous studies (e.g., McFerran et al., 2010) suggest that moral identity and moral personality are two separate elements, in our conceptual model, we posit that moral identity moderates the relationship between collaborative learning and employee proactiveness to engage with responsible and sustainable consumption. Further studies might foresee the effects of both moral personality and moral identity on employee proactiveness to engage with sustainable consumption and assess employee propensity to disengage (McFerran et al., 2010) with irresponsible consumption.

Second, previous studies report that social context in video gaming has been found to be an important dimension (Gentile, 2008). Thus, empirical findings could yield different results for studies conducted using a large group online video game in comparison to a small group online video game as a requirement of more collaborative efforts, such as good communication and teamwork, which cannot be applied when playing solo or in small groups as the difficulty level is marginal and there is little need to collaborate in the same way as playing in a large group video game.

Third, our manuscript is purely conceptual and to puts forward propositions rather than hypotheses. Therefore, to test those propositions both a quantitative approach along with a qualitative data collection methods, followed by a quantitative study, could be used to gain deeper insights into massively multiplayer online video game players to explain how online video games could contribute to improve employee responsiveness to be engaged with responsible and sustainable consumption within the three key areas responsible for the highest proportion of $\mathrm{CO} 2$ emissions: food, mobility and housing.

\section{Acknowledgement}

We would like to thank the editor for helpful guidance. This research was funded by a grant (No. S-MIP-17-123) from the Research Council of Lithuania.

\section{References}

Adams, R. N. (2016) Global games market report: games to earn \$99.6 billion in 2016 (accessed on 27 January, 2017 https://techraptor.net/content/global-games-market-report-2016). 
Bakker, A., Tims, M., \& Derks, D. (2012). Proactive personality and job performance: the role of job crafting and work engagement. Human Relations, 65(10), 1359-1378. https://doi.org/10.1177/0018726712453471

Bandura, A. (1977). Social learning theory. Englewood Cliffs, NJ: Prentice Hall.

Barclay, L. J., Whiteside, D. B., \& Aquino, K. (2014). To avenge or not to avenge? Exploring the interactive effects of moral identity and the negative reciprocity norm. Journal of Business Ethics, 121(1), 15-28. https://doi.org/10.100 7/s10551-013-1674-6

Bargh, J. A., \& Schul, Y. (1980). On the cognitive benefits of teaching. Journal of Educational Psychology, 72, $593-604$. https://doi.org/10.1037/0022-0663.72.5.593

Barrick, M. R., Stewart, G. L., \& Piotrowski, M. (2002). Personality and job performance: Test of the mediating effects of motivation among sales representatives. Journal of Applied Psychology, 87(1), 43-51.https://doi.org/10.1037 /00219010.87.1.43

Bartle, R. A. (2004). Designing virtual worlds. Berkeley, CA: New Riders Games.

Bartle, R. A. (1996). Hearts, clubs, diamonds, spades: Players who suit MUDs. Retrieved from http://www.mud.co.uk/ri chard/hcds.htm

BBC news. (2005). Retrieved from http://news.bbc.co.uk/1/hi/technology/4137782.stm, accessed 04 October, 2018

Benabou, R., \& Tirole, J. (2003). Intrinsic and extrinsic motivation. Review of Economic Studies, 70, 489-520. https://doi.org/10.1111/1467-937X.00253

Brasington, R. (1990). Nintendinitis. New England Journal of Medicine, 322(20), 1473-1474. https://doi.org/10.1056/ NEJM199005173222020

Buckley, K. E., \& Anderson, C. A. (2006). A theoretical model of the effects and consequences of playing video games. Chapter in P. Vorderer \& J. Bryant (Eds.), Playing Video Games - Motives, Responses, and Consequences (pp. 363378). Mahwah, NJ: LEA.

Chen, G., \& Chiu, M. (2008). Online discussion processes. Computers and Education, 50, 678. https://doi.org/10.1016/ j.compedu.2006.07.007

Chiu, M. M. (2008). Effects of argumentation on group micro-creativity. Contemporary Educational Psychology, 33, 383402. https://doi.org/10.1016/j.cedpsych.2008.05.001

Chowdhury, R. M. M., \& Fernando, M. (2014). The relationship of empathy, moral identity and cynicism with consumers ethical beliefs: The mediating role of moral disengagement. Journal of Business Ethics, 124(4), 677-694. https://doi.org/10.1007/s10551-013-1896-7

Crant, J. M. (2000) Proactive behavior in organizations. Journal of Management, 26, 435-462. https://doi.org/10.11 77/014920630002600304

Crimston, D., Bain, P. G., Hornsey, M. J., \& Bastian, B. (2016). Moral expansiveness: Examining variability in the extension of the moral world. Journal of Personality and Social Psychology, 111(4), 636-653.https://doi.org/10. 1037/pspp0000086

De Mattos C., \& Salciuviene, L. (2017). The negative influence of the entrepreneur's level of higher education on the attractiveness of European SMEs as alliance partners in Brazil: the role of practical experience and international entrepreneurial orientation. The International Journal of Human Resource Management, 1-29.https://doi.org/10. 1080/09585192.2017.1316758

Dillenbourg, P. (1999) Collaborative learning: Cognitive and computational approaches. New York, NY: Elsevier Science, Inc.

FAO. (2013). FAO Statistical Year Books - World Food and Agriculture. Retrieved from http://www.fao.org/docrep/ 018/i3107e/i3107e04.pdf. (Last accessed: October 26, 2018).

Gentile, D. A., Anderson, C. A., Yukawa, S., Ihori, N., Saleem, M., Ming, L. K., Shibuya, A., Liau, A. K., Khoo, A., Bushman, B. J., Huesmann, L. R., \& Sakamoto, A. (2009). The effects of Prosocial Video games on Prosocial Behaviors: international evidence from correlational, longitudinal, and experimental studies. Society for Personality and Social Psychology, 35(6), 752-763. https://doi.org/10.1177/0146167209333045

Granic, I., Lobel, A., \& Engels, R. C. M. E. (2014). The benefits of playing video games. American Psychologist, 69(1), 66-78. https://doi.org/10.1037/a0034857

Hamalainen, R., Manninen, T, Jarvela, \& Hakkinen, O. (2006). Leaning to collaborate: designing collaboration in a 3-D game environment. The Internet and Higher Education, 9(1), 47-61. https://doi.org/10.1016/j.iheduc.2005.12.004

Hart, D., Atkins, R., \& Ford, D. (1998). Urban America as a context for the development of moral identity in adolescence. Journal of Social Issues, 54(3), 513-530. https://doi.org/10.1111/j.1540-4560.1998.tb01233.x

Hazel, J. (2018a) The Social Benefits of Games: Clinical Research, 3 May, 2018. Retrieved from https://checkpoint.org.au/the-social-benefits-of-games-clinical-research/. (Last accessed: October 21, 2018). 
Laura Salciuviene, Veronica C. Buenaventura, Kelvin Lee. Employee Proactiveness to Engage in Sustainable...

Hazel, J. (2018b). The Psychological and Emotional Benefits of Video Games: Clinical Research, 24 January, 2018. Retrieved from https://checkpoint.org.au/psychological-emotional-benefits-video-games-clinical-research/. (Last accessed: October 22, 2018).

Hertwich, E. G., \& Peters, G. P. (2009). Carbon footprint of nations: a global trade-linked analysis. Environmental Science Technology, 43, 6414-6420.Harford, T. (2017). The surprising ways video games have shaped the economy, 19 June, 2017. Retrieved from https://www.bbc.co.uk/news/business-40028628. (Last accessed: October 22, 2018).

Hovland, C. I. (1938). Experimental studies in rote-learning theory. I. Reminiscence following learning by massed and by distributed practice. Journal of Experimental Psychology, 22(3), 201-224. https://doi.org/10.1037/h0062123

Howe, N., \& Strauss, B. (2000). Millennials rising: The next great generation. New York, NY: Vintage Books.

Jia, F., Soucie, K., Alisat, S., Curtin, D., \& Pratt, M. (2017). Are environmental issues moral issues? Moral identity in relation to protecting the natural world. Journal of Environmental Psychology, 52, 104-113. https://doi.org/10.10 16/j.jenvp.2017.06.004

Karmarkar, U. R., \& Bollinger, B. (2015). BYOB: How bringing your own shopping bags leads to treating yourself and the environment. Journal of Marketing, 79(4), 1-15. https://doi.org/10.1509/jm.13.0228

Kollar, P. (2016). Did Legion boost World of Warcraft's subscriber numbers over 10 million? (accessed on 27 October, 2016 http://www.polygon.com/2016/10/4/13167592/world-of-warcraft-legion-subscriber-numbers-10-million)

Kong, J., \& Kwok, R. (2009). MMOG Game-Based Collaborative Learning: An Exploratory Study and its Research Potential. Paper presented at the 2009 Pacific Asia conference on Information Systems, Hyderabad, India.

Kushner, D. (2005) Engineering Everquest. IEEE Spectrum Online. Retrieved from http://www.spectrum.ieee.org/ jul05/1561

Laister, J., \& Koubek, A. (2001). 3rd generation learning platforms requirements and motivation for collaborative learning. European Journal of Open, Distance and E-Learning. Retrieved from http://www.eurodl.org/?article=54

Lipkin, N. A., \& Perrymore, A. J. (2009) Y in the workplace: Managing the "me first" generation. Franklin Lakes, NJ: The Career Press, Inc.

Liu, W., Oosterveer, P., \& Spaargaren, G. (2016). Promoting sustainable consumption in China. Journal of Cleaner Production, 134, 13-21. https://doi.org/10.1016/j.jclepro.2015.10.124

Lumpkin, G. T. (2011). From legitimacy to impact: Moving the field forward by asking how entrepreneurship informs life. Strategic Entrepreneurship Journal, 5, 3-9. https://doi.org/10.1002/sej.104

Masgoret, A. M., \& Garder, R. C. (2003). Attitudes, motivation, and second language learning: A meta-analysis of studies conducted by gardner and Associates. Language Learning, 53(1), 167-210. https://doi.org/10.1111/1467-9922.00227

Mayer, D. M., Aquino, K. Greenbaum, R. I., \& Kuenzi, M. (2012). Who displays ethical leadership, and why does it matter? An examination of antecedents and consequences of ethical leadership. Academy of Management Journal, 2012, 55(1), 151-171. https://doi.org/10.5465/amj.2008.0276

McFerran, B., Aquino, C., \& Duffy, M. (2010). How personality and moral identity related to individual's ethical ideology. Business Ethics Quarterly, 20(1), 35-56.https://doi.org/10.5840/beq20102014

McGonigal, J (2010). Reality is broken: Why games make us better and how they can change the world [kindle 3 version]. retrieved from http://www.amazon.com

McHugh, D., Groves, D., \& Alker, A. (1998). Managing learning: what do we learn from a learning organization? The Learning Organization, 5(5), 209-220.https://doi.org/10.1108/09696479810238215

McLaren, D., \& Childs, M. with contributions from Shrubsole, G. (2013) Consumption and Identity, Friends of Earth. Retrieved from https://cdn.friendsoftheearth.uk/sites/default/files/downloads/consumption-identity-18135.pdf. (Last accessed: 25 October, 2018).

McLeod (2016). Bandura - Social Learning Theory. Retrieved from https://www.simplypsychology.org/bandura.html [Accessed on 04 October, 2018]

Mischel, W., \& Shoda, Y. (1995). A cognitive-affective system theory of Personality: reconceptualizing situations, dispositions, dynamics, and invariance in personality structure. Psychological Review, 102, $246-268$. https://doi.org/10.1037/0033-295X.102.2.246

Nardi, B., \& Harris, J. (2006). ). "Strangers and friends: collaborative play in World of Warcraft." Proceedings of the 2006 20th Anniversary Conference on Computer Supported Cooperative Work, pp. 149-158. New York: AcM Press. https://doi.org/10.1145/1180875.1180898

Nohria, N., Groysberg, B., \& Lee, L. (2008). Employee motivation: a powerful new model. Harvard Business Review, $86(7 / 8), 78-84$.

O'Keeffe, T. (2002). Organizational learning: a new perspective. Journal of European Industrial Training, $26(2), 130-141$. https://doi.org/10.1108/03090590210422012

O'Reilly, J. (2010) The World of Warcraft Demographics. retrieved from http://www.articlesbase. com/computer-gamesarticles/the-world-of-warcraft-demographics-2856963.html

Panitz, T. (1997). The case for student centered instruction via collaborative learning paradigms. Retrieved from http://home.capecod.net/ tpanitz/tedsarticles/coopbenefits.htm 
Perkins, N. L. (1914). The value of distributed repetitions in rote learning. British Journal of Psychology, 7(2), 253261.https://doi.org/10.1111/j.2044-8295.1914.tb00113.x

Piaget, J. (1972). The psychology of the child. New York: Basic Books.

Pintrich, P. R. (1999). The role of motivation in promoting and sustaining self-regulated learning. International Journal of Educational Research, 31(6), 459-470. https://doi.org/10.1016/S0883-0355(99)00015-4

Reed, A., II, Kay, A., Finnel, S., Aquino, K., \& Levy, E. (2016). I don't want the money, I just want your time: How moral identity overcomes the aversion to giving time to prosocial causes. Journal of Personality and Social Psychology, 110(3), 435-457. https://doi.org/10.1037/pspp0000058

Rodriguez-Rad, Carlos J., \& Ramos-Hidalgo, Encarnacion (2018). Spirituality, consumer ethics, and sustainability: the mediating role of moral identity. Journal of Consumer Marketing, 35(1), 51-63. https://doi.org/10.1108/JCM-122016-2035

Sansone, C., \& Hawackiewicz, J. M. (2000). Intrinsic and extrinsic motivation: the search for optimal motivation and performance. San Diego, CA. Century Business.

Schultheiss, D. (2007). Long-term motivations to play MMOGs: A longitudinal study on motivations, experience and behavior. Paper presented at the situated Play digital games research Association, Tokyo, Japan.

Seibert, S. E., Kraimer, M. L., \& Crant, J. M. (2001). What do proactive people do? A longitudinal model linking proactive personality and career success. Personnel Psychology, 54, 845-874. https://doi.org/10.1111/j.1744-6570.2 001.tb00234.x

Senge, P. M. (1990). The fifth discipline: the art and practice of the learning organization. London, UK: Century Business.

Shih, C., \& Gamon, J. (2001). Web-based learning: relationships among students motivation, attitude, learning styles and achievement. Journal of Agricultural Education, 42, 12-20. https://doi.org/10.5032/jae.2001.04012

Simpson, P. (2015). 3 Truths about millennials and gamers. Retrieved from https://www.dmnews.com/customerexperience/article/13036136/3-truths-about-millennials-and-gaming [Accessed on 04 October, 2018]

Spaargaren, G. (2011) Theories of practices: Agency, technology, and culture: Exploring the relevance of practice theories for the governance of sustainable consumption practices in the new world-order. Global Environmental Change, 21, 3, 813-822. https://doi.org/10.1016/j.gloenvcha.2011.03.010

Steinkuehler, C. A. (2004b). Online cognitive ethnography: Methods for studying massively multiplayer online videogaming culture. Paper presented at the 17th Annual conference on interdisciplinary Qualitative studies, Athens, Georgia.

Steinkuehler, C. A. (2004a) Learning in massively multiplayer online games. Paper presented at the international conference on Learning Sciences, Santa Monica, CA.

Stone, W., \& Gentile, D. A. (2008). The five dimensions of video game effects. Paper presented at the Annual convention of the American Psychological Association, Boston, Massachussets.

Subrahmanyam, K., Kraut, R. E., Greenfield, P. M., \& Gross E. F. (2000). The impact of home computer use on children's activities and development. The Future of Children - Children and Computer Technology, 10(2), 123-144.

Takahashi, D. (2016). Global market games forecast to hit \$100B by 2019 (accessed on 27 January, 2017 http://venturebeat.com/2016/03/14/global-games-market-forecast-to-hit-100b-by-2019/)

Tapscott, D. (2009). Grown up digital: How the net generation is changing your world. New York, NY: Mcgraw-Hill.

Voulgari, I., \& Komis, V. (2011). On studying collaborative learning interactions in massively multiplayer online games. Poster paper to be presented in Vs-games 2011 conference, Athens, Greece. https://doi.org/10.1109/VSGAMES.2011.36

Watkins, L., Aitken, R., \& Mather, D. (2016). Conscientious consumers: a relationship between moral foundations, political orientation and sustainable consumption. Journal of Cleaner Production, 134(A), 137-146.

Weiner, B. (1972). Theories of motivation: From mechanism to cognition. Oxford, England: Markham.

Wooliscroft, B., Ganglmair-Wooliscroft, A., \& Noone, A. (2013). The hierarchy of ethical consumption behaviour: the case of New Zealand. Journal of Macromarketing, 34, pp. 57-72. https://doi.org/10.1177/0276146713508560

Wu, B., \& Yang, Z. (2018). The impact of moral identity on consumers' green consumption tendency: The role of perceived responsibility for environmental damage. Journal of Environmental Psychology, 59, 74-84. https://doi.org/10.1016/j.jenvp.2018.08.011

Yee, N. (2005). MMORPG Hours vs. TV Hours. Retrieved from http://www.nickyee.com/daedalus/archives/000891.php

Yee, N. (2006). The demographics, motivations and derived experiences of users of massively-multiuser online graphical environments. PRESENCE: Teleoperators and Virtual Environments, 15, 309-329. https://doi.org/10.11 62/pres.15.3.309

Yee, N. (2007). Motivations of play in online games. Journal of CyberPsychology and Behaviour, 9, $772-775$. https://doi.org/10.1089/cpb.2006.9.772

The article has been reviewed.

Received in November 2017; accepted in February 2019. 